\title{
Optical Emission Spectroscopic Analysis of Plasma Plume during Pulsed Laser Deposition of PZT
}

\author{
S. Sasanka Kumar, ${ }^{1}$ R. Reshmi, ${ }^{2}$ N. V. Joshy, ${ }^{3}$ A. C. Saritha, ${ }^{1}$ and M. K. Jayaraj ${ }^{1}$ \\ ${ }^{1}$ Nanophotonic and Opto Electronic Devices Lab, Department of Physics, Cochin University of Science and Technology, \\ Cochin, Kerala 682022, India \\ ${ }^{2}$ Department of Physics, UC College, Aluva, Kerala 683102, India \\ ${ }^{3}$ Department of Physics, St. Pauls College, Kalamasserry, Kerala 682022, India
}

Correspondence should be addressed to M. K. Jayaraj; jayaraj.mk@gmail.com

Received 23 October 2013; Revised 3 January 2014; Accepted 4 January 2014; Published 13 February 2014

Academic Editor: Keli Han

Copyright (C) 2014 S. Sasanka Kumar et al. This is an open access article distributed under the Creative Commons Attribution License, which permits unrestricted use, distribution, and reproduction in any medium, provided the original work is properly cited.

\begin{abstract}
Spatial variation in intensity of spectral emission, electron temperature, number density, and the time of flight (TOF) of ions and neutrals at various oxygen ambiances has been investigated on ferroelectric lead zirconium titanate (PZT) plasma using optical emission spectroscopy. Plasma produced by ablating PZT ceramic target using Nd-YAG laser operating at the third harmonics $(\lambda=355 \mathrm{~nm}, \tau=10 \mathrm{~ns}$, repetition frequency $10 \mathrm{~Hz})$ was investigated at various oxygen partial pressures and at various distances from the target surface. Here energy density for laser fluence was fixed as $3.13 \mathrm{Jcm}^{-2}$ and distance from the target and ambient gas pressure were varied. The electron number density $N_{e}$ and electron temperature of the PZT plasma at the early stage of plume expansion were measured as $1.7 \times 10^{17} \mathrm{Jcm}^{-2}$ and $13200 \mathrm{~K}$, respectively, and thus verified the existence of local thermodynamic equilibrium (LTE). Time of flight spectra (TOF) of neutral and singly ionized species in plasma were recorded. The result shows that plasma parameters and velocity of species are of same order for various oxygen partial pressures but have a decreasing tendency with distance. The energy of almost all species in the plume become more or less same at 0.1 mbar. These conditions favour the growth of perovskite PZT thin films.
\end{abstract}

\section{Introduction}

Pulsed laser deposition (PLD) is a versatile tool for the deposition of multilayer and multicomponent thin film heterostructures in a single pump down cycle with many advantages such as low temperature processing, low level of contamination, reproduction of the target stoichiometry on thin films, and reproducibility of film characteristics $[1,2]$. Therefore, the PLD has attracted much attention for the synthesis of thin films of a variety of materials, such as high temperature superconductors [3-5], ferroelectrics [6,7], and metal compounds [8]. Lead zirconium titanate (PZT) with composition $\left(\mathrm{Pb}\left[\mathrm{Zr}_{0.52} \mathrm{Ti}_{0.48}\right] \mathrm{O}_{3}\right)$ is a multicomponent insulator target material having ferroelectric, ferroelastic [911], and piezoelectric [12] properties interwined with its pervoskite structure, from which thin films were grown by laser ablation. These ferroelectric films have promising applications in optoelectronic devices and for ferroelectric random access memory (FRAM) $[13,14]$. The growth of perovskite PZT films by pulsed laser deposition is, however, very complicated due to the preferential occurrences of the pyrochlore phase, zirconium rich phase, and $\mathrm{Pb}$ loss $[15,16]$.

The properties of thin films deposited by pulsed laser ablation (PLA) are closely related to the dynamics and the composition of the laser generated plasma [17-19]. The plume produced in vacuum at the immediate vicinity of the target undergoes isentropic and adiabatic expansion [20-25] which has been studied in detail by Anisimov et al. [26, 27] and Singh et al. $[28,29]$. But the interaction of the plume with an ambient gas involves more complex gas dynamic process which depends on the target stoichiometry, laser fluence and spot size. In the presence of ambient gas, species in the plume gets decelerated and attenuated due to the enhanced collision 
with the background gas. This results in plasma confinement and generation of shock waves.

The radiation emitted from the excited species on the plume was analysed using optical emission spectroscopy (OES). OES is a nonintrusive method and hence the plasma properties can be analysed for the entire length of the plume rather than first $10 \mathrm{~mm}$. Previous study have shown that laser energy density or gas pressure plays a vital role in determining the kinetic energies of species reaching the substrate, thus influencing the morphology and stoichiometry of the deposited films $[18,30]$. The difference in shape of the plume observed in vacuum and oxygen ambience reveals that expansion in background gas differs from that of free expansion. In the present study we investigate the possible reason for the necessity of high oxygen ambiance for the growth of pervoskite PZT thin film [31]. The effect of background gas on plume expansion and subsequent deposition was explained using shock and drag model following Gonzalo et al. [32] and Kushwaha and Thereja [33].

\section{Experimental}

The experimental setup used for the investigation has been reported previously [34] and features relevant to the present study are summarized here. Third harmonic of Q switched Nd:YAG laser (Quanta Ray, Spectra Physics) operating at $355 \mathrm{~nm}, 10 \mathrm{~Hz}$ repetition frequency, and pulse width $10 \mathrm{~ns}$ was used for ablation. The 1:1 image of the plume developed during pulsed laser ablation was imaged to a plane where the optical fibre was placed. Optical fibre which is kept on an $X-Y$ translator collects the light flux at various spatial positions of the plume along the plume propagation direction. This was fed into a $1 / 3$-meter spectrometer [TRIAX-320] which was calibrated by recording the spectrum of mercury lamp in the range of $570-580 \mathrm{~nm}$. The two adjacent peaks of $\mathrm{Hg}$ were identified as shown in Figure 1 and then we compared those with the standard wavelength. The resolution of the spectrometer is given by the equation

$$
\delta \lambda=\frac{\mathrm{FWHM}}{a} \times \delta A,
$$

where $\delta A$ is difference in the standard wavelength. " $a$ " is the distance between the two peaks of $\mathrm{Hg}$ lines observed using the spectrometer. Using this equation we found the resolution of our spectrometer as $\sim 0.14 \mathrm{~nm}$. The slit width and integration time of the spectrometer for the present study are $70 \mu \mathrm{m}$ and $0.5 \mathrm{sec}$, respectively.

The base pressure of the ablation chamber was $2 \times$ $10^{-6}$ mbar. The laser beam was focused on to the target to a spot size of $1.0 \mathrm{~mm}$, energy density $3.13 \mathrm{Jcm}^{-2}$. The variation of plasma parameters such as electron temperature, number density, and time of flight of various species up to $10 \mathrm{~mm}$ from the target surface were recorded using LIBS technique. The ablation was carried out in $2 \times 10^{-6} \mathrm{mbar}$ at $0.001 \mathrm{mbar}$, $0.01 \mathrm{mbar}$, and $0.1 \mathrm{mbar}$ pressures of oxygen ambience. The wavelength dispersed spectra of the plume were recorded using monochromator-CCD assembly and the time of flight of respective species was recorded using a photomultiplier

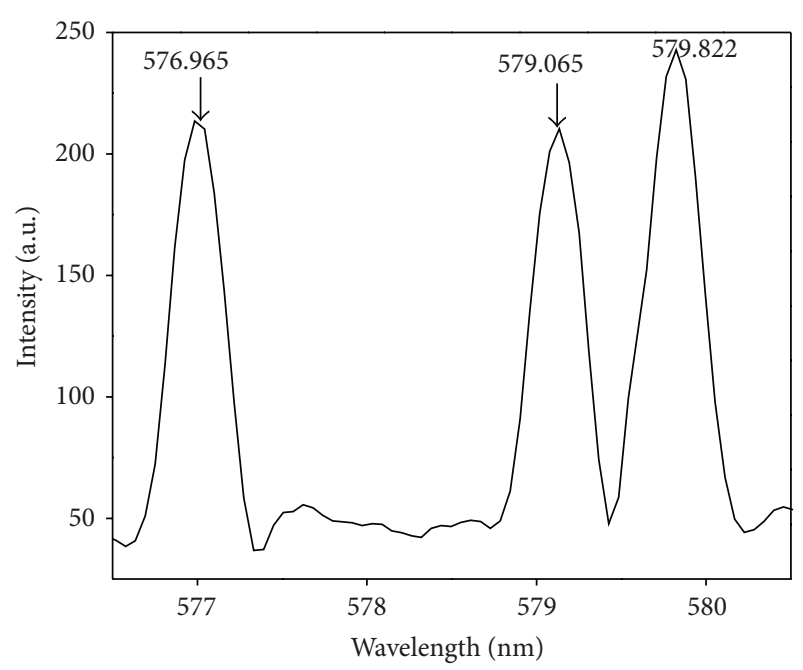

FIgURE 1: The Hg emission lines recorded using Triax 320 spectrometer.

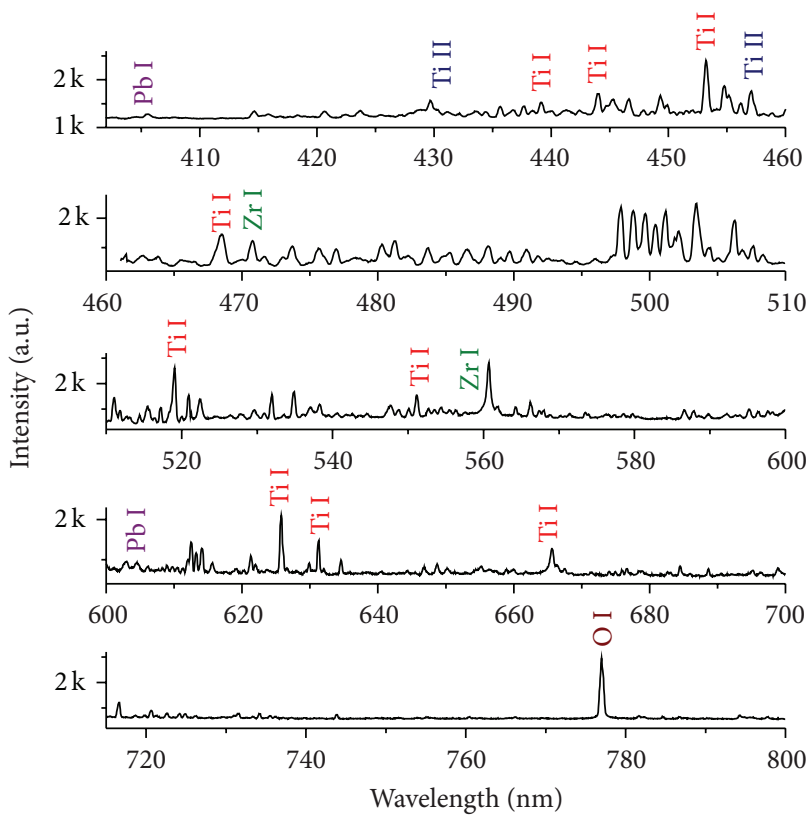

FIGURE 2: Wavelength-dispersed emission spectrum of PZT plume recorded at $3 \mathrm{~mm}$ from the target surface along the normal at laser fluence of $3.13 \mathrm{Jcm}^{-2}$ and oxygen pressure of $0.1 \mathrm{mbar}$.

tube (Hamamatsu) and digital storage oscilloscope (Tektronix TDS 2014) [34].

\section{Results and Discussions}

3.1. Spectral Intensity. Figure 2 shows the recorded wavelength dispersed spectra of the plume. The spectrum mainly consists of neutral and singly ionized species of titanium, zirconium, oxygen, and lead. Integral intensity of various spectral lines is calculated by taking the stark broadened emission profile. The spatial variation in integral intensity of neutral and ionic species present in PZT plasma at 

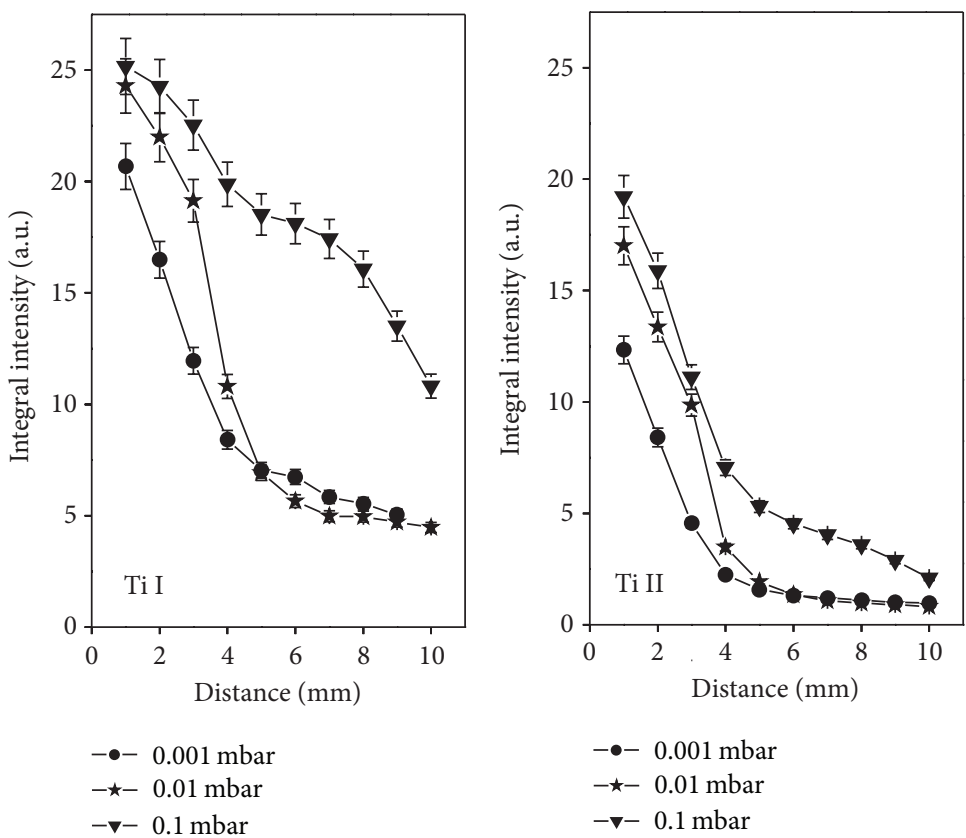

FIGURE 3: The spatial variation of integral intensity of Ti I [453.34 nm] and Ti II [522.54 nm] at 0.001 mbar, $0.01 \mathrm{mbar}$, and $0.1 \mathrm{mbar}$ oxygen pressures for the laser fluence of $3.13 \mathrm{Jcm}^{-2}$.
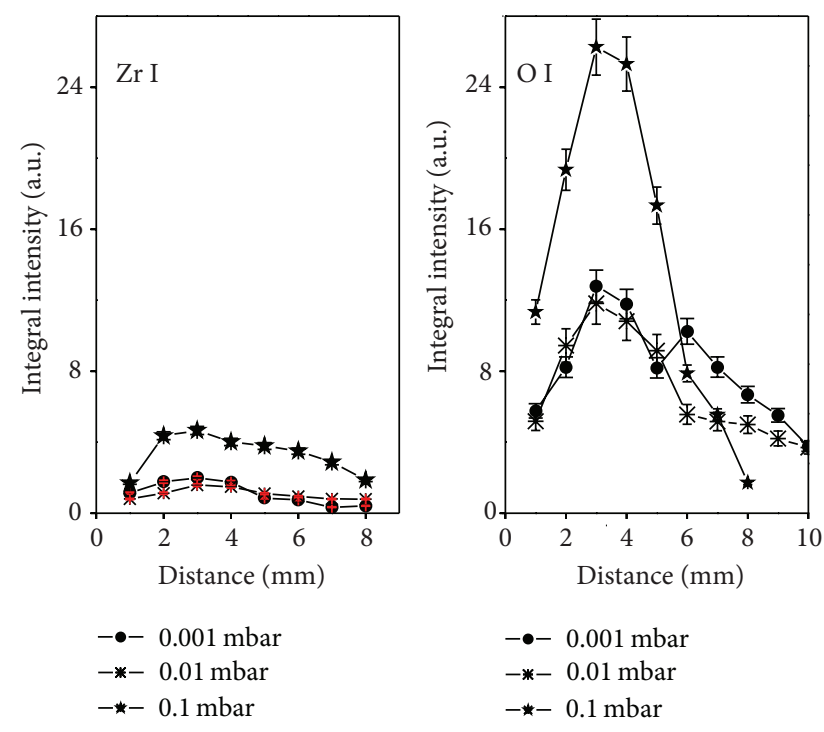

Figure 4: The spatial variation of integral intensity of $\mathrm{Zr}$ $(470.98 \mathrm{~nm})$ and $\mathrm{O}(777.5 \mathrm{~nm})$ at $0.001 \mathrm{mbar}, 0.01 \mathrm{mbar}$, and $0.1 \mathrm{mbar}$ oxygen pressures for the laser fluence of $3.13 \mathrm{Jcm}^{-2}$.

various ambient pressures has been recorded. The spatial variation of integral intensity of Ti I [453.34 nm] and Ti II [522.64 nm] ablated at $0.001 \mathrm{mbar}, 0.01 \mathrm{mbar}$, and $0.1 \mathrm{mbar}$ oxygen pressures for the laser fluence of $3.13 \mathrm{Jcm}^{-2}$ is shown in Figure 3, and that of Zr I [561.21 nm] and O I [777.65] is shown in Figure 4. The increase in integral intensity with the increase of background pressure shows an increase of collisional excitation. Also on comparing the variation of integral intensity of neutrals and ions of $\mathrm{Ti}$ at $0.1 \mathrm{mbar}$ pressure, there is a sharp decrease in intensity beyond a distance of $3 \mathrm{~mm}$ from the target for ionic species and a hump for neutral, which indicates a collisional recombination. Similar behaviour was shown by ions and neutrals of $\mathrm{Pb}$. The integral intensity of neutral zirconium and oxygen (Figure 4) shows an initial tendency to increase along the propagation direction of the plume up to $3 \mathrm{~mm}$. But it suffers severe attenuation beyond $3 \mathrm{~mm}$ from the target surface. So the plume front showed a tendency to attain a hemispherical shape and the plume expansion feels severe constraints which lead to the formation of shock waves [35-37] at plume-target interface with the increase of oxygen ambience. This shock wave produces metastable species of plasma constituents in the plume by electron impact excitation. The rapid decrease in the emission intensity observed beyond certain distance from the target as reported in literature $[38,39]$ corresponds to many processes that take place in plasma plume such as the decrease in the electron impact excitation due to the collisions of the constituent species of the target with excited neutrals and background gas during expansion of the plume [40], the production of negative ions [41] by the attachment of electron to super excited oxygen molecule $[42,43]$. The intensity of the emission lines attenuated after a distance of $\sim 1 \mathrm{~cm}$ from the target. This does not mean that the respective species in the plume ceased after this distance. This reduction in emission intensity may be due to the non radiative decay resulting from the adiabatic expansion of the plume species. The velocities and the K.E of all the species still have sufficient velocities (Figure 8) to move forward and reach the substrate to form thin films. 


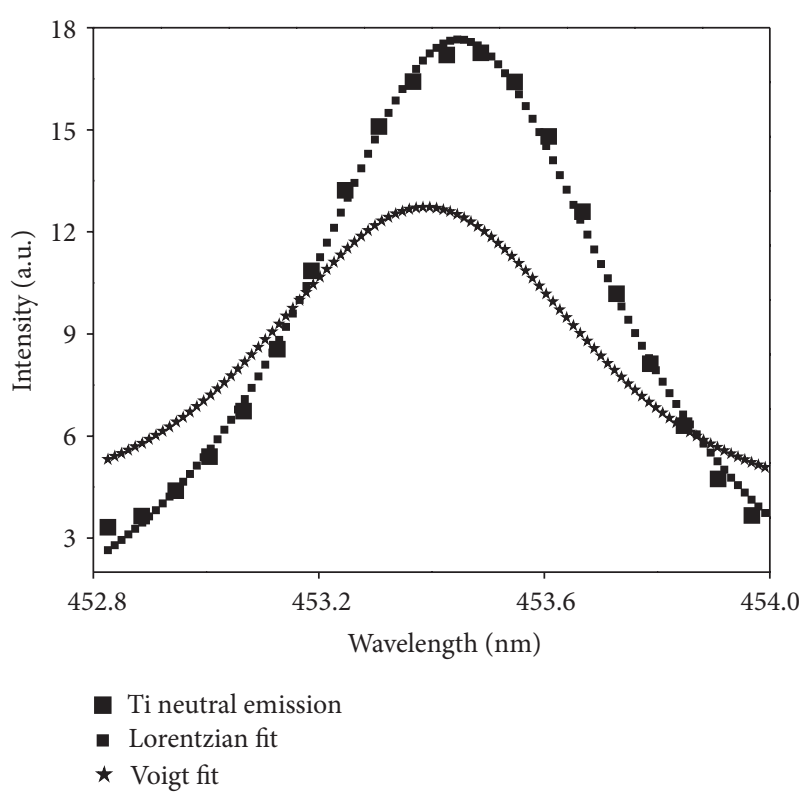

Figure 5: Lorentzian and Voigt fit on emission line of Ti I.

3.2. Electron Density and Temperature. The details of OES technique used for determining $N_{e}$ have been described elsewhere [34, 35]. The emission profile of $453.34 \mathrm{~nm}$ line which exhibits perfect Lorentzian fit used for the calculation of $N_{e}$ is shown in Figure 5. The spectral line analysis for the present study was made by fitting the line shapes to numerically generated Voigt profiles and with them making the deconvolution to obtain the Lorentzian profile resulted from stark broadening and Gaussian profile from Doppler broadening and instrumental broadening. The experimental profile used for measuring instrumental error is the observed mercury lines shown in Figure 2. The instrumental error in measuring plasma parameters is estimated by generating a Voigt profile numerically fitted with the experimental emission profile. Thus we measured the error in measuring plasma parameters as $\leq 5 \%$. Lorentzian fraction was found to be significant for the measurement of electron temperature and density in our experiment. The ratio of emission line intensities of successive ionization states of the same element was used for the determination of electron temperature of the plume. The emission line intensities of $501.41 \mathrm{~nm}$ and $522.38 \mathrm{~nm}$, respectively, of Ti I and Ti II have been used for the determination of electron temperature. The atomic data needed for the calculation were taken from NIST atomic database $[44,45]$. The electron density $\left(N_{e}\right)$ and temperature show a gradual decrease with distance from the target surface at 0.001 and $0.1 \mathrm{mbar}$ oxygen ambiance for laser fluence $3.13 \mathrm{Jcm}^{-2}$ (Figure 6). The plume shrinkage with increase in pressure is a well-known phenomenon in LIP [38]. The plasma is confined $[32,41,46,47]$ to smaller volume on elevated ambient pressure. The observed small variation of the temperature and number density could be due to the time averaging of these values. Laser plasma properties change rapidly with space and time and these changes are drastic at closer distance and early times. The ions in the plasma plume

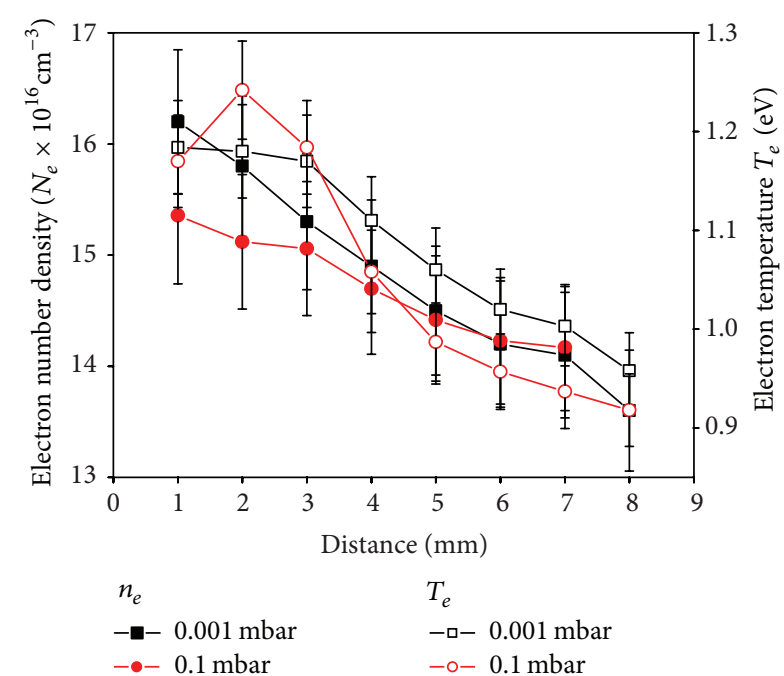

FIGURE 6: Spatial variation of electron density and temperature at different pressures along the surface normal at laser fluence of $3.13 \mathrm{Jcm}^{-2}$.

gets accelerated due to the formation of double layers at early times and shorter distance from the target as evidenced by Bulgakova et al. [48] and Wood et al. [49] which may be a possible reason for the increase of temperature for $0.1 \mathrm{mbar}$ pressure levels at shorter distances.

Using the measured electron density and temperature the existence of LTE plasma in our experiment is verified using necessary (but not sufficient) condition $[44,45]$ :

$$
n_{e} \geq 6.7 \times 10^{11}\left(T_{e}\right)^{1 / 2}(\delta E)^{3} \mathrm{~cm}^{-3},
$$

where $n_{e}$ is the minimum electron density for LTE to exist, $T_{e}$ is the plasma temperature (in $\mathrm{K}$ ), and $(\delta E)$ is the largest energy difference expected in the transitions (in $\mathrm{eV}$ ). With plasma having temperature $13200 \mathrm{~K},(\delta E)$ of $2.735 \mathrm{eV}, n_{e}$ should exceed $10^{15} \mathrm{~cm}^{-3}$ for LTE to exist. The measured values of electron density at all pressures are found to be higher than this, thereby suggesting that the plasma is at LTE. The electron temperature values of the plume at various spatial points along the surface normal calculated for $3.13 \mathrm{Jcm}^{-2}$ at two oxygen pressures are shown in Figure 6.

3.3. Time of Flight Studies (TOF). Optical emission spectroscopic studies showed that most of the species present in the laser produced PZT plumes under the present experimental conditions are singly ionized and excited neutrals [37] of the target and the background gas. In OES, the dynamics of various species of the plume was studied by selecting strong emission lines of individual elements using the monochromator coupled with PMT. The current output from the PMT was dropped across $50 \mathrm{ohm}$ resistor and fed to $100 \mathrm{MHz}$ digital storage oscilloscope (Tektronix TDS 2014). The oscilloscope was interfaced with a computer for storage and subsequent processing of time of flight (TOF) spectra. To elucidate the influence of an ambient gas on various species in the plume, TOF profiles were taken at different distances 


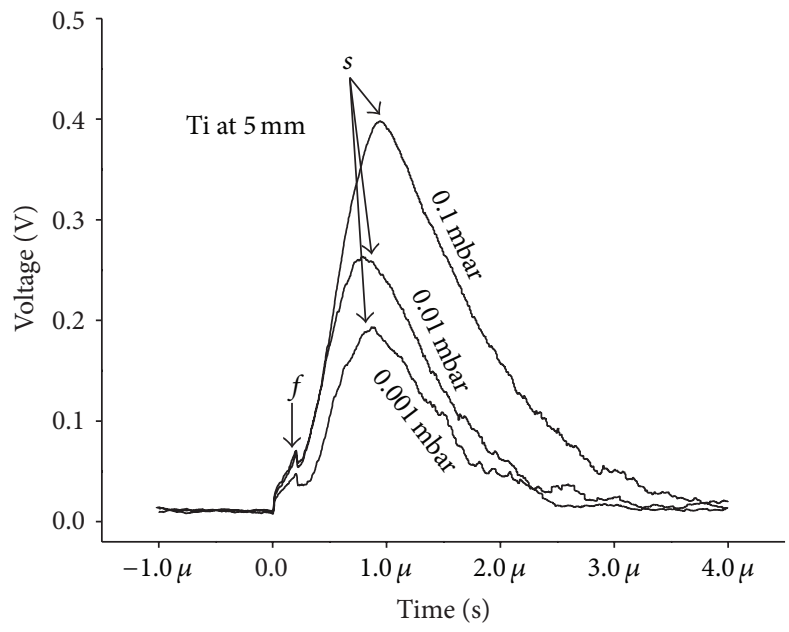

(a)

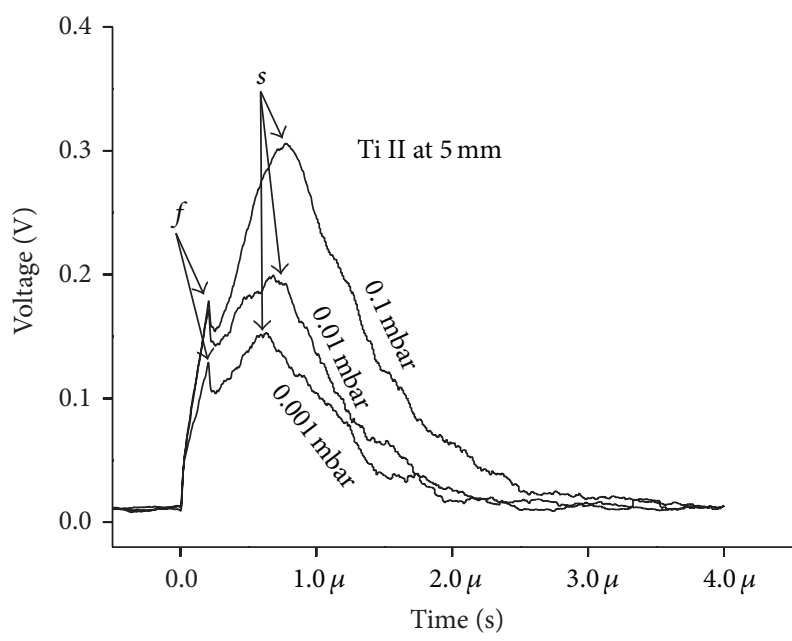

(c)

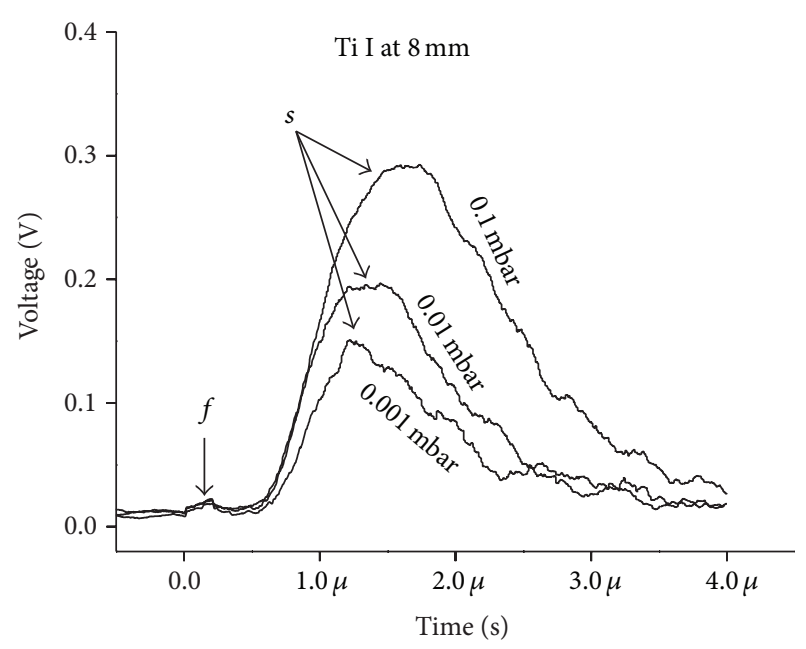

(b)

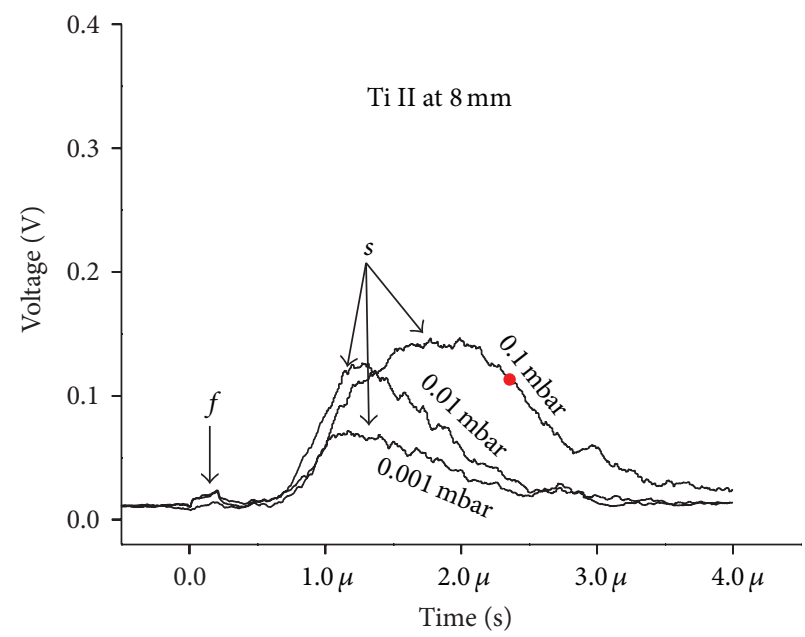

(d)

FIgure 7: The TOF of Ti I (neutral) ((a) and (b)) and Ti II (ion) ((c) and (d)) at distances $5 \mathrm{~mm}$ and $8 \mathrm{~mm}$ from the target at pressures 0.1 , 0.01 , and $0.001 \mathrm{mbar}$ at laser fluence of $3.13 \mathrm{Jcm}^{-2}$. " $f$ " denote the fast peak and " $s$ " denotes the slow one.

from the target surface. TOF studies of the plume give vital information regarding the time taken by a particular state of the constituent species evolving after onset of plasma. This technique gives details on the velocity and hence kinetic energy of the emitted particles [50].

The TOF of Ti (I) and Ti (II) at spatial distances (5 mm and $8 \mathrm{~mm})$ at pressures $(0.1,0.01$, and $0.001 \mathrm{mbar})$ at laser fluence of $3.13 \mathrm{Jcm}^{-2}$ is shown in Figures $7(\mathrm{a})-7(\mathrm{~d})$. The increase in oxygen partial pressure increases the intensity of the emission lines of all the species but delayed the arrival time. This is in accordance with the impedance offered to the forward propagation of the plume and there by generating shock wave which increases the collisional excitation [37,39]. In all these graphs there is a fast peak (f) along with the slow one (s). This fast peak can be attributed to the shock wave generation due to phase explosion followed by plume expansion associated with the laser matter interaction [48]. But the intensity of this fast peak goes on decreasing with increase in distance from the target as shown in Figures 7(a)$7(\mathrm{~d})$, which reveals that these two mechanisms are obtained only at the immediate vicinity just above the Knudsen layer on the target.

The spatial variation in velocities and the respective kinetic energies of $\mathrm{Zr} \mathrm{I}$, Ti I, O I Pb I, and $\mathrm{Pb}$ II at 0.1 and $0.001 \mathrm{mbar}$ is shown in Figure 8. The velocity and the corresponding energy of different species in plasma show some random behaviour at $0.001 \mathrm{mbar}$ pressure which tends to be ordered at $0.1 \mathrm{mbar}$. The velocities were found to be of the order of $10^{3} \mathrm{~m} / \mathrm{sec}$ that undergoes no order change with spatial variation. But the velocity and corresponding energies of the species in the plume at $0.1 \mathrm{mbar}$ pressure (Figure 8 ) affects the drag discussed earlier due to the ripples formed due to shock waves. So, even if the integral intensities of all emission lines attenuated beyond $10 \mathrm{~mm}$ distance from the target during plasma expansion, the plasma particle whether ionic or otherwise does not get perished at these distances. 

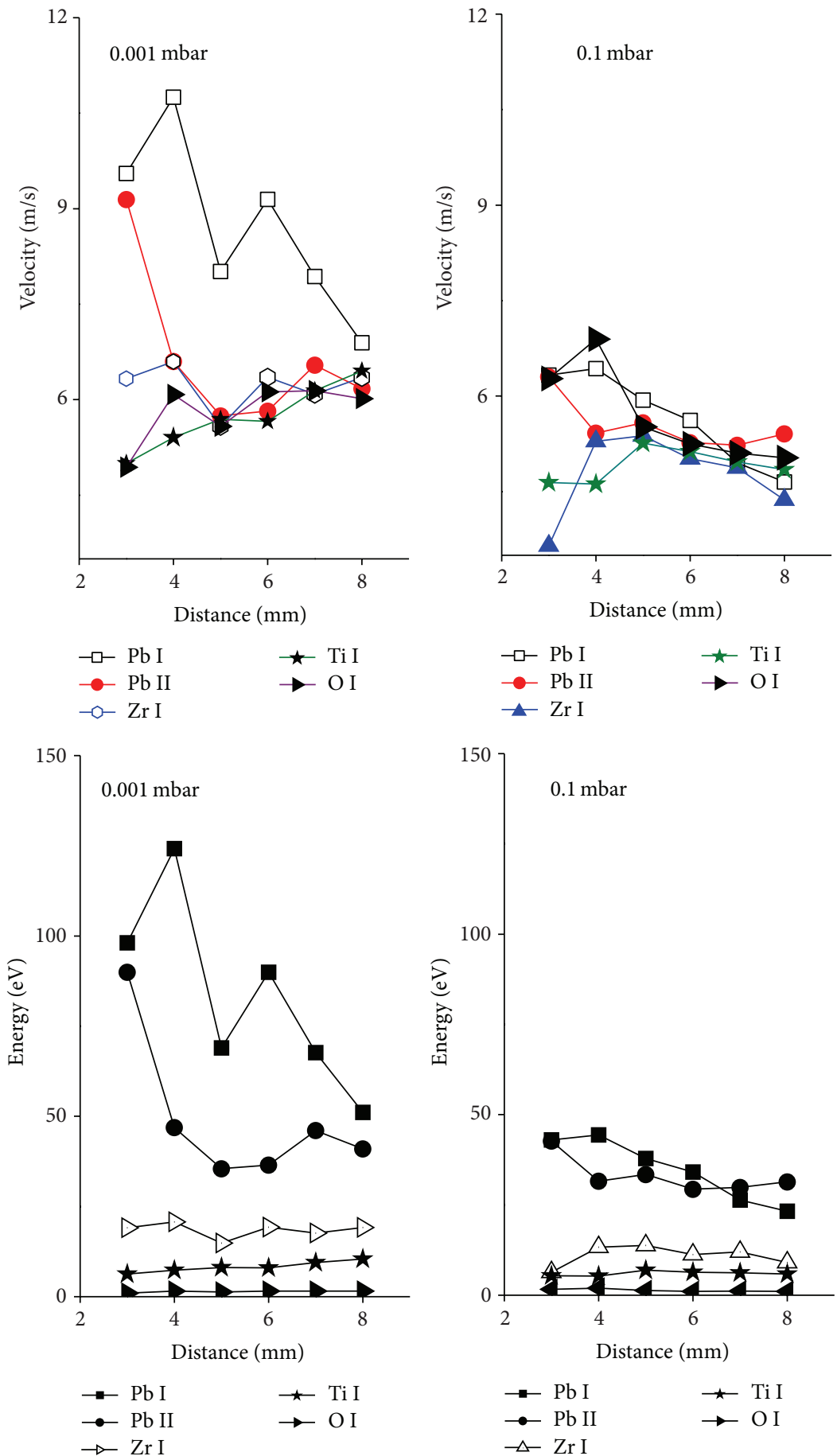

FIGURE 8: The spatial variation in velocities and the respective kinetic energies of Zr I, Ti I, and O I at 0.1 and 0.001 mbar oxygen ambiance.

The particles will have sufficient energies, as seen from their respective velocities and energies (Figure 8), and can reach the substrate. The effect of variation in the oxygen pressure leading to the formation of pervoskite PZT thin film after annealing at a temperature of $600^{\circ} \mathrm{C}$ is shown in Figure 9.

Films deposited at various oxygen ambiances $\left(2 \times 10^{-6}\right.$, $0.001,0.01$, and 0.1 mbar) was annealed at different temperatures ranging from 400 to $750^{\circ} \mathrm{C}$. Among these, the films deposited at low pressures such as $2 \times 10^{-6}, 0.001$, and $0.01 \mathrm{mbar}$ were amorphous even on annealing up to $750^{\circ} \mathrm{C}$ as shown in Figures 9(a)-9(c). But film deposited at $0.1 \mathrm{mbar}$ forms pyrochlore and pervoskite phase of PZT, respectively, at $500^{\circ} \mathrm{C}$ and at $600^{\circ} \mathrm{C}$ annealing temperature as shown in Figures $9(\mathrm{~d})$ and $9(\mathrm{e})$. This shows that for the crystalline formation, deposition pressure plays a greater role rather than annealing temperature for PZT; that is, the amplitude of 


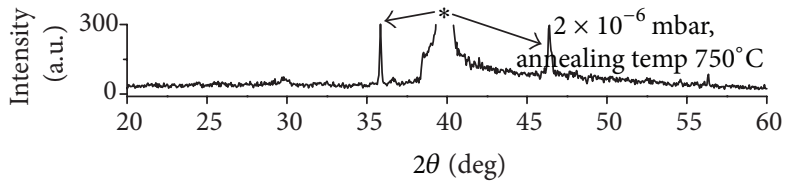

(a)

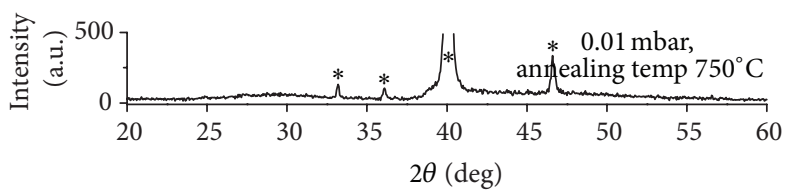

(c)

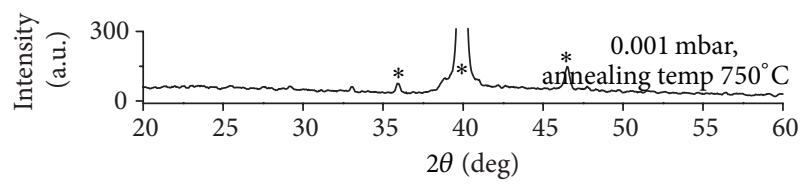

(b)

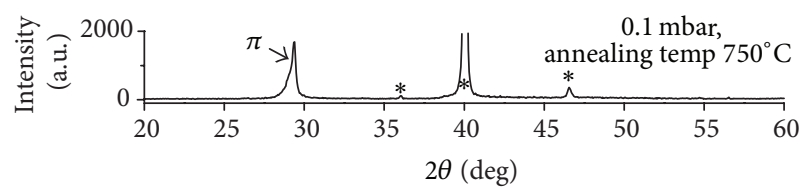

(d)

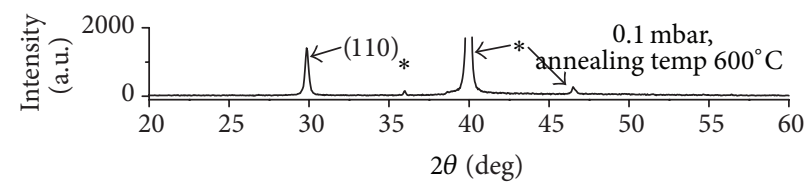

(e)

FIgURE 9: The XRD pattern of PZT thin films deposited at different pressures $2 \times 10^{-6}$ mbar to $0.1 \mathrm{mbar}((\mathrm{a})$ to (d)) and then annealed at $750^{\circ} \mathrm{C}$ and $500^{\circ} \mathrm{C}$ and $(\mathrm{e})$ at $600^{\circ} \mathrm{C}(\pi$ represents the pyrochlore phase and $*$ represents substrate).

shock wave formed at low pressure is not sufficient to activate the chemical reaction in the plume. So the occurrence of crystalline formation at $0.1 \mathrm{mbar}$ pressure can be be attributed to the evidence that the amplitude of shock waves produced at this pressure may be sufficient to activate the chemical reaction on the species in the plume and background gas which corroborates with our discussion in the plume study.

\section{Conclusion}

The result presented here clearly shows that the plasma expansion dynamics are strongly affected by the presence of oxygen environment as observed from the revival of excitation and ionization of the plume species at higher pressures. Confinement of plasma results in shock wave formation to regions close to the target for high pressure was evident from the decrease of emission intensity and slowing down of ejected species. The evolution of temperature, number density, and time of flight of species in plasma shows a pressure dependence. That is, at high pressure, the shock wave originating zone in the plume may activate the chemical reaction between ejected metastable species and the super excited ambient gas molecules will be a possible reason for the requirement of high pressure in order to retent the pervoskite phase during thin film deposition. X-ray diffraction patterns of the films deposited at various pressures corroborate with the results.

\section{Conflict of Interests}

The authors declare that they have no conflict of interests regarding the publication of this paper.

\section{Acknowledgment}

One of the author, S. S. Kumar, thanks the University Grant Commission (UGC) for the Junior Research Fellowship under UGC-RFSMS scheme.

\section{References}

[1] Y. Yamagata, A. Sharma, J. Narayan, R. M. Mayo, J. W. Newman, and K. Ebihara, "Optical emission study of ablation plasma plume in the preparation of diamond-like carbon films by $\mathrm{KrF}$ excimer laser," Journal of Applied Physics, vol. 86, no. 8, pp. 41544159, 1999.

[2] J. R. Duclere, M. G. Viry, A. Perrin, and E. Cattan, "Ferroelectric (116) $\mathrm{SrBi}_{2} \mathrm{Nb}_{2} \mathrm{O}_{9}$ thin films epitaxially grown by pulsed laser deposition on epitaxial (110) $\mathrm{Pt} /(110) \mathrm{SrTiO}_{3}$ electrode," Applied Physics Letters, vol. 81, no. 11, article 2067, 2002.

[3] E. W. Chase, T. Venkatesan, C. C. Chang et al., "Multilayer high Tc thin film structures fabricated by pulsed laser deposition of Y-Ba-Cu-O," Journal of Materials Research, vol. 4, no. 6, pp. 1326-1329, 1989.

[4] J. Schubert, M. Siegert, M. Fardmanesh et al., "Superconducting and electro-optical thin films prepared by pulsed laser deposition technique," Applied Surface Science, vol. 168, no. 1-4, pp. 208-214, 2000.

[5] A. N. Jannah, S. A. Halim, and H. Abdullah, "Superconducting properties of BSCCO thin films by pulsed laser deposition," European Journal of Scientific Research, vol. 29, no. 4, pp. 438446, 2009.

[6] K. M. Satyalakshmi, M. Alexe, A. Pignolet, N. D. Zakharov, and D. Hessei, " $\mathrm{BaBi}_{4} \mathrm{Ti}_{4} \mathrm{O}_{15}$ ferroelectric thin films grown by pulsed laser deposition," Applied Physics Letters, vol. 74, no. 4, article 603, 1999. 
[7] Y. Yang, Z. Wang, J.-F. Li, and D. Viehland, "Pulsed laser deposition of $\mathrm{BaTiO}_{3}$ thin films on different substrates," Journal of Nanomaterials, vol. 2010, Article ID 756319, 5 pages, 2010.

[8] J. G. Lunney, "Pulsed laser deposition of metal and metal multilayer films," Applied Surface Science, vol. 86, no. 1-4, pp. 79-85, 1995.

[9] F. Craciun, M. Dinescu, P. Verardi, and C. Galassi, "Pulsed laser deposition of nanocrystalline lead zirconate titanate thin films," Nanotechnology, vol. 10, no. 1, pp. 81-85, 1999.

[10] V. Koval, M. J. Reece, and A. J. Bushby, "Ferroelectric/ferroelastic behavior and piezoelectric response of lead zirconate titanate thin films under nanoindentation," Journal of Applied Physics, vol. 97, no. 7, Article ID 074301, 2005.

[11] B. Clausen, R. C. Rogan, E. Üstundag, M. R. Daymond, and V. Knoblauch, "Ferroelastic behavior of PZT-based ferroelectric ceramics," Materials Science Forum, vol. 404-407, pp. 413-418, 2002.

[12] Y. Ehara, S. Yasui, J. Nagata et al., "Ultrafast switching of ferroelastic nanodomains in bilayered ferroelectric thin films," Applied Physics Letters, vol. 99, no. 18, Article ID 182906, 2011.

[13] D. Ambika, V. Kumar, K. Tomioka, and I. Kannno, "Deposition of PZT thin films with $\{001\},\{110\}$, and $\{111\}$ crystallographic orientations and their transverse piezoelectric characteristics," Advanced Materials Letters, vol. 3, no. 2, pp. 102-106, 2012.

[14] P. K. Larsen, G. A. C. M. Spierings, R. Cuppens, and G. J. M. Dormans, "Ferroelectrics and high permittivity dielectrics for memory applications," Microelectronic Engineering, vol. 22, no. 1-4, pp. 53-60, 1993.

[15] T. Nakamura, Y. Fukuda, A. Yogo et al., "Coulomb implosion mechanism of negative ion acceleration in laser plasmas," Physics Letters A, vol. 373, pp. 2584-2587, 2009.

[16] Y. Yao, S. G. Lu, H. Chen, J. Zhai, and K. H. Wong, "Role of oxygen pressure during pulsed laser deposition on the electrical and dielectric properties of antiferroelectric lanthanum-doped lead zirconate stannate titanate thin films," Journal of Applied Physics, vol. 96, article 569, 2004.

[17] F. U. Din, S. A. Halim, A. Kamalianfar et al., "Modeling of superconducting ybco thin films by short pulse laser deposition," Journal of Ovonic Research, vol. 8, no. 1, pp. 9-15, 2012.

[18] A. V. Bulgakov and N. M. Bulgakova, "Dynamics of laserinduced plume expansion into an ambient gas during film deposition," Journal of Physics D, vol. 28, no. 8, p. 1710, 1995.

[19] E. Gyorgy, C. Ristoscu, I. N. Mihailescu et al., "Role of laser pulse duration and gas pressure in deposition of AIN thin films," Journal of Applied Physics, vol. 90, no. 1, pp. 456-461, 2001.

[20] B. Dogget and J. G. Lunney, "Expansion dynamics of laser produced plasma," Journal of Applied Physics, vol. 109, Article ID 093304, 2011.

[21] M. Capitelli, A. Casavola, G. Colonna, and A. De Giacomo, "Laser-induced plasma expansion: theoretical and experimental aspects," Spectrochimica Acta B, vol. 59, no. 3, pp. 271-289, 2004.

[22] D. B. Doumaz and M. Djebl, "Effect of ionization on laserinduced plume self-similar expansion," Applied Surface Science, vol. 255, no. 8, pp. 4595-4599, 2009.

[23] S. S. Harilal, C. V. Bindhu, M. S. Tillack, F. Najmabadi, and A. C. Gaeris, "Internal structure and expansion dynamics of laser ablation plumes into ambient gases," Journal of Applied Physics, vol. 93, no. 5, pp. 2380-2388, 2003.

[24] N. Kumar, S. Dash, A. K. Tyagi, and B. Raj, "Dynamics of plasma expansion in the pulsed laser material interaction," Sadhana, vol. 35, no. 4, pp. 493-511, 2010.
[25] T. Mościcki, J. Hoffman, and Z. Szymański, "Modelling of plasma formation during nanosecond laser ablation," Archives of Mechanics, vol. 63, pp. 99-116, 2011.

[26] S. I. Anisimov, D. Bauerle, and B. S. Lukyanchuk, "Gas dynamics and film profiles in pulsed-laser deposition of materials," Physical Review B, vol. 48, no. 16, pp. 12076-12081, 1993.

[27] S. I. Anisimov, B. S. Luk'yanchuk, and A. Luches, "An analytical model for three-dimensional laser plume expansion into vacuum in hydrodynamic regime," Applied Surface Science, vol. 9698, pp. 24-32, 1996.

[28] R. K. Singh, O. W. Holland, and J. Narayan, "Theoretical model for deposition of superconducting thin films using pulsed laser evaporation technique," Journal of Applied Physics, vol. 68, article 233, 1990.

[29] R. K. Singh and J. Narayan, "Pulsed-laser evaporation technique for deposition of thin films: physics and theoretical model," Physical Review B, vol. 41, no. 13, pp. 8843-8859, 1990.

[30] J. Gonzalo, C. N. Afonso, and J. Perrière, "Influence of laser energy density on the plasma expansion dynamics and film stoichiometry during laser ablation of $\mathrm{BiSrCaCuO}$," Journal of Applied Physics, vol. 79, no. 10, article 8042, 1996.

[31] R. Reshmi, V. Natarajan, and M. K. Jayaraj, "Effect of buffer layer on the properties of laser ablated PZT thin films," Integrated Ferroelectrics, vol. 117, no. 1, pp. 104-109, 2010.

[32] J. Gonzalo, C. N. Afonso, and I. Madariaga, "Expansion dynamics of the plasma produced by laser ablation of $\mathrm{BaTiO}_{3}$ in a gas environment," Journal of Applied Physics, vol. 81, no. 2, pp. 951955, 1997.

[33] A. Kushwaha and R. K. Thereja, "Dynamics of laser-ablated carbon plasma: formation of $\mathrm{C}_{2}$ and $\mathrm{CN}$," Applied Optics, vol. 47, no. 31, pp. G65-G71, 2008.

[34] K. J. Saji, N. V. Joshi, and M. K. Jayaraj, "Optical emission spectroscopic studies on laser ablated zinc oxide plasma," Journal of Applied Physics, vol. 100, no. 4, Article ID 043302, 2006.

[35] N. V. Joshi, K. J. Saji, and M. K. Jayaraj, "Spatial and temporal studies of laser ablated ZnO plasma," Journal of Applied Physics, vol. 104, no. 5, Article ID 053307, 2008.

[36] J. Francois, Y. Gravel, and D. Boudreau, "Study by focused shadowgraphy of the effect of laser irradiance on laser-induced plasma formation and ablation rate in various gases," Spectrochimica Acta B, vol. 64, no. 1, pp. 56-66, 2009.

[37] P. Hough, T. J. Kelly, C. Fallon et al., "Enhanced shock wave detection sensitivity for laser-produced plasmas in low pressure ambient gases using interferometry," Measurement Science and Technology, vol. 23, no. 12, Article ID 025204, 2012.

[38] S. B. Wen, X. Mao, R. Greif, and R. E. Russo, "Expansion of the laser ablation vapor plume into a background gas. I. Analysis," Journal of Applied Physics, vol. 101, no. 2, Article ID 023114, 2007.

[39] Z. Rui, L. Z. Cheng, H. Bing et al., "Mechanism of laser-induced plasma shock wave evolution in air," Chinese Physics B, vol. 18, no. 5, pp. 1877-1883, 2009.

[40] C. Timmer, S. K. Srivastava, T. E. Hall, and A. F. Fucaloro, "Enhanced line emission from laser-produced plasmas," Journal of Applied Physics, vol. 70, no. 3, pp. 1888-1890, 1991.

[41] H. P. Gu, Q. H. Lou, N. H. Cheung, S. C. Chen, Z. Y. Wang, and P. K. Lin, "Experimental study of enhanced emission of the laser-ablated plume in backing gas," Applied Physics B, vol. 58, no. 2, pp. 143-148, 1994.

[42] S. Amoruso, J. Schou, and J. G. Lunney, "Ablation plume dynamics in a background gas," in Proceedings of the International High Power Laser Ablation Symposium (HPLA '10), vol. 1278 of AIP 
Conference Proceedings, pp. 665-676, Santa Fe, NM, USA, April 2010.

[43] M. Esposito, M. Bator, M. Döbeli, T. Lippert, C. W. Schneider, and A. Wokaun, "Negative ions: the overlooked species in thin film growth by pulsed laser deposition," Applied Physics Letters, vol. 99, no. 19, Article ID 191501, 2011.

[44] H. R. Griem, Plasma Spectroscopy, McGraw Hill, New York, NY, USA, 1964.

[45] G. Bekfi, Laser Plasma Spectroscopy, John Willey \& Sons, New York, NY, USA, 1976.

[46] H. F. Sakeek, T. Morrtow, W. G. Graham, and D. G. Walmsley, "Emission studies of the plume produced during $\mathrm{YBa}_{2} \mathrm{Cu}_{3} \mathrm{O}_{7}$ film production by laser ablation," Journal of Applied Physics, vol. 75, article 1140, 1994.

[47] J. Gonzalo, F. Vega, and C. N. Afonso, "Plasma expansion dynamics in reactive and inert atmospheres during laser ablation of $\mathrm{Bi}_{2} \mathrm{Sr}_{2} \mathrm{Ca}_{1} \mathrm{Cu}_{2} \mathrm{O}(7-y)$," Journal of Applied Physics, vol. 77, article 6588, 1995.

[48] N. M. Bulgakova, A. V. Bulgakova, and O. F. Bobernok, "Double layer effects in laser-ablation plasma plumes," Physical Review E, vol. 62, no. 4, pp. 5624-5635, 2000.

[49] R. F. Wood, J. N. Leboeuf, D. B. Geohegan, A. A. Puretzky, and K. R. Chen, "Dynamics of plume propagation and splitting during pulsed-laser ablation of Si in He and Ar," Physical Review B, vol. 58, no. 3, pp. 1533-1543, 1998.

[50] S. S. Harilal, B. O. Shay, Y. Tao, and M. S. Tillack, "Ambient gas effects on the dynamics of laser-produced tin plume expansion," Journal of Applied Physics, vol. 99, no. 8, Article ID 083303, 2006. 

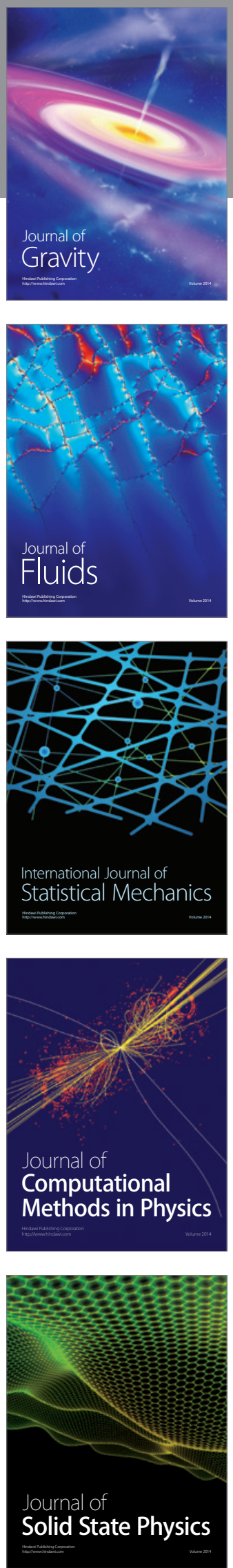

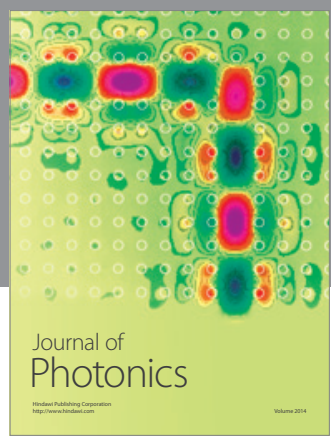

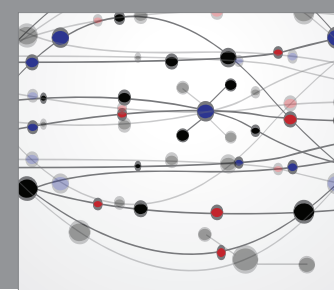

The Scientific World Journal

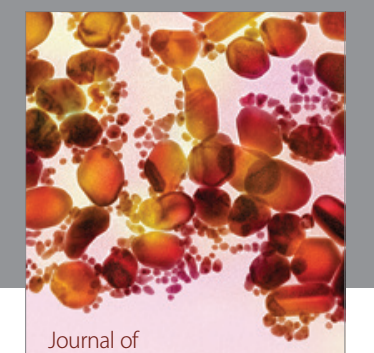

Soft Matter
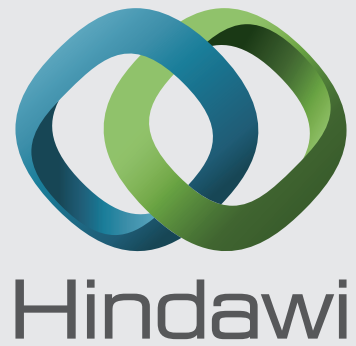

Submit your manuscripts at

http://www.hindawi.com
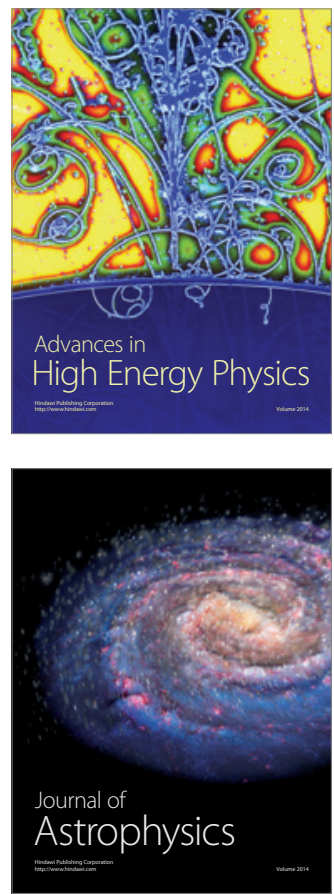
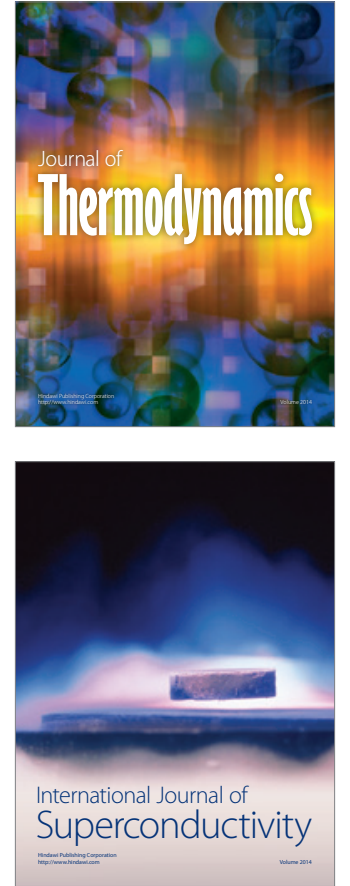
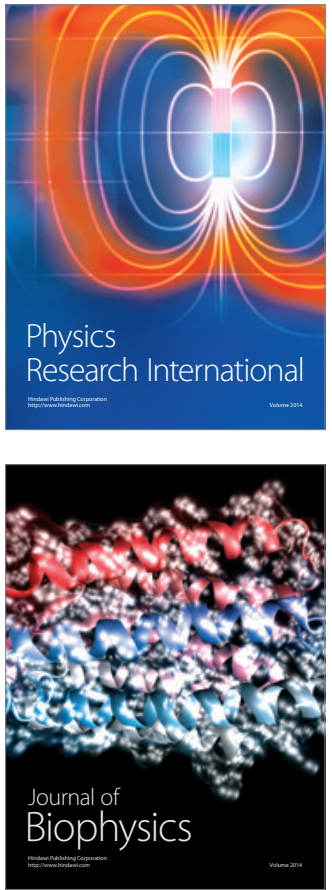
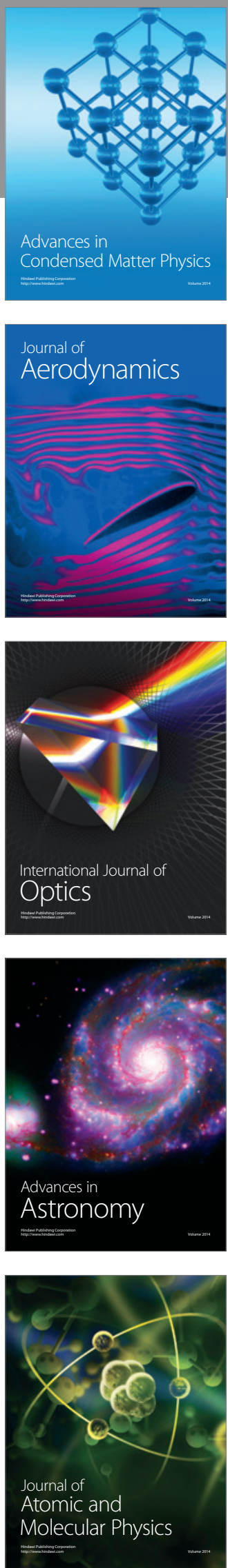